\title{
Spontaneous reversal of nystagmus in the dark
}

\author{
Fatima S Shawkat, Christopher M Harris, David S I Taylor
}

\begin{abstract}
Aim-To report five children with horizontal jerk nystagmus in whom eye movement recordings in the dark revealed a spontaneous reversal in the direction of the nystagmus beat. Three patients were blind in one eye and were diagnosed as having a manifest latent nystagmus (MLN), and two patients had strabismus and congenital nystagmus $(\mathrm{CN})$.

Methods-Eye movements were recorded using DC electro-oculography with simultaneous video recording, including infrared recording in total darkness.

Results-Four patients had decelerating velocity slow phase jerk nystagmus when recorded under natural lighting conditions; the fifth case had accelerating velocity and linear slow phase jerk nystagmus. Under absolute darkness, nystagmus reversed in direction of beat with a mixture of linear and decelerating velocity slow phase waveforms. One child with unilateral anophthalmos could wilfully reverse the beat direction of his nystagmus by trying to look with his blind eye in the light and dark.

Conclusions-These observations support the theory that LN/MLN beat direction is determined by the "presumed" viewing eye and may be consciously controlled. The spontaneous reversal of beat direction in the dark suggests eye dominance is predetermined. Eye movement recordings identified mixed nystagmus waveforms indicating that $\mathrm{CN}$ (accelerating velocity slow phases) and LN/MLN (linear/ decelerating velocity slow phases) coexist in these subjects.

(Br F Ophthalmol 2001;85:428-431)
\end{abstract}

Department of

Ophthalmology, Great

Ormond Street

Hospital for Children

NHS Trust, London

WC1 N 3JH, UK

F S Shawkat

C M Harris

D S I Taylor

Plymouth Institute of Neuroscience, University of Plymouth, Drake

Circus, Plymouth, UK

C M Harris

Correspondence to: Dr Shawkat

fatima@gordonreid.net

Accepted for publication 13 December 2000
Pure latent nystagmus ( $\mathrm{LN})$ is a conjugate jerk nystagmus that is only present on occlusion of one eye: it is not evident with both eyes viewing. It is characterised by a linear or decelerating velocity exponential slow phase and the direction of the quick phase is towards the uncovered eye: if the right eye is covered the nystagmus beats to the left, if the left eye is covered the nystagmus direction reverses and beats to the right. If vision in one eye is low, $\mathrm{LN}$ may be manifested on binocular viewing and is known as manifest latent nystagmus (MLN). Monocularly, the nystagmus is usually present in primary gaze, although in some it may only become evident on abduction of the viewing eye. In most cases the nystagmus dampens in adduction but accentuates in abduction of the viewing eye: this may lead to the adoption of a head turn in the direction of the fixing eye that would minimise the nystagmus. LN/MLN is usually secondary to early onset disruption of binocular vision and is commonly associated with infantile esotropia as well as uniocular congenital visual defects such as cataracts. ${ }^{12}$

There have been two reports in the literature, which have described the ability of patients to alter their latent nystagmus at will. Kommerell and $\mathrm{Zee}^{3}$ described two patients who with voluntary effort could release or suppress their latent nystagmus, which always beat in the direction of the patient's dominant eye. Dell'Osso et $a l^{4}$ reported one patient who had his right eye enucleated due to glaucoma, secondary to persistent hyperplastic primary vitreous. The patient had MLN (beating to the left) and in the dark, the nystagmus spontaneously reversed in beat direction (beating to the right). This patient was also able to wilfully reverse his MLN in the dark by alternating his supposed fixing eye.

This report describes the eye movement findings in five young children with manifest jerk nystagmus, which spontaneously reversed in the direction of beat when they were placed in the dark. Furthermore, one child could intentionally reverse the direction of his nystagmus beat.

\section{Methods}

Children presenting with nystagmus are usually referred to the eye movement unit for evaluation of their nystagmus. Horizontal eye movements were recorded using bitemporal DC electro-oculography with simultaneous video monitoring, including infrared monitoring in total darkness. ${ }^{5}$ Eye movements were recorded in primary position and all cardinal points of gaze in the light and dark. Eye movements were calibrated by recording reflexive saccades to light emitting diodes at 10 and 20 degrees to left and right of centre. As part of the routine assessment eye movements are examined and recorded in total darkness.

\section{Results}

Five children with manifest jerk nystagmus showed a spontaneous reversal of nystagmus beat direction in the dark. The nystagmus waveforms varied between patients and accelerating velocity slow phases, a hallmark of $\mathrm{CN}$, as well as decelerating velocity and linear slow phase were present. The ability to wilfully change the nystagmus beat direction was found in one child who when asked, could "look" through his blind eye in the light or dark and reverse the direction of his nystagmus quick phases.

Table 1 summarises the patient details and nystagmus characteristics.

\section{CASE REPORTS}

Case 1

The eye movements in this boy were recorded when he was 4 years old. The patient had 
Table 1 Clinical details of patients with spontaneous reversal of nystagmus in the dark

\begin{tabular}{|c|c|c|c|c|c|c|c|}
\hline Case & Sex & $\begin{array}{l}\text { Age at } \\
\text { testing } \\
\text { (years) }\end{array}$ & Diagnosis & $\begin{array}{l}\text { Acuities } \\
\text { (Snellen) }\end{array}$ & Eye movements in the light & Eye movements in the dark & Handedness \\
\hline 1 & M & 4 & $\begin{array}{l}\text { Congenital } \\
\text { nystagmus }\end{array}$ & $\begin{array}{l}\text { RE } 6 / 7.5 \\
\text { LE } 6 / 6\end{array}$ & $\begin{array}{l}\text { Horizontal left beating nystagmus with mixed } \\
\text { linear and accelerating slow phase velocities. } \\
\text { Nystagmus pronounced in all directions of gaze } \\
\text { but dampens in right gaze. Occlusion of right } \\
\text { eye does not alter nystagmus but left eye } \\
\text { occlusion results in right beating nystagmus. }\end{array}$ & $\begin{array}{l}\text { Spontaneous right beating nystagmus } \\
\text { with predominantly linear slow phases. }\end{array}$ & Right \\
\hline 2 & $\mathrm{~F}$ & 4 & $\begin{array}{l}\text { Tuberous sclerosis } \\
\text { and L convergent } \\
\text { squint }\end{array}$ & $\begin{array}{l}\text { RE } 6 / 12 \\
\text { LE } 6 / 24\end{array}$ & $\begin{array}{l}\text { Horizontal right beating nystagmus in all } \\
\text { directions of gaze. The slow phases were of } \\
\text { decelerating velocity. Occlusion of left eye does } \\
\text { not alter nystagmus but right eye occlusion } \\
\text { elicits left beating nystagmus. }\end{array}$ & $\begin{array}{l}\text { Spontaneous left beating nystagmus } \\
\text { with decelerating and linear slow phase } \\
\text { velocities. The nystagmus in the dark } \\
\text { was of larger amplitude than that } \\
\text { recorded in the light. }\end{array}$ & Right \\
\hline 3 & $\mathrm{~F}$ & 7 & $\begin{array}{l}\mathrm{L} \text { microphthalmia } \\
\text { and retinal } \\
\text { dysplasia }\end{array}$ & $\begin{array}{l}\text { RE } 6 / 9 \\
\text { LE NPL }\end{array}$ & $\begin{array}{l}\text { Fine horizontal right beating nystagmus in all } \\
\text { directions of gaze, more marked in right gaze, } \\
\text { dampens slightly in left gaze. Slow phases were } \\
\text { of decelerating velocity. }\end{array}$ & $\begin{array}{l}\text { Spontaneous left beating nystagmus } \\
\text { with linear and decelerating slow phase } \\
\text { velocities. }\end{array}$ & Right \\
\hline 4 & M & 9 & L Peter's anomaly & $\begin{array}{l}\text { RE } 6 / 6 \\
\text { LE PL }\end{array}$ & $\begin{array}{l}\text { Fine horizontal right beating nystagmus that } \\
\text { accentuated in lateral gaze without changing in } \\
\text { direction of beat. The slow phases were of } \\
\text { decelerating and linear velocities. }\end{array}$ & $\begin{array}{l}\text { Spontaneous marked left beating } \\
\text { nystagmus of larger amplitude than } \\
\text { that recorded in the light. Slow phases } \\
\text { were of decelerating and linear } \\
\text { velocities. }\end{array}$ & Left \\
\hline 5 & M & 9 & $\mathrm{R}$ anophthalmos & $\begin{array}{l}\text { RE NPL } \\
\text { LE } 6 / 9\end{array}$ & $\begin{array}{l}\text { Moderate amplitude horizontal left beating } \\
\text { nystagmus in all directions of gaze, becoming } \\
\text { more intense on left gaze and dampening in } \\
\text { right gaze. The slow phase velocities were } \\
\text { mixed linear and decelerating. This child could } \\
\text { change the direction of his nystagmus by trying } \\
\text { to look with his blind eye. }\end{array}$ & $\begin{array}{l}\text { Spontaneous right beating linear slow } \\
\text { phase velocity nystagmus. He could } \\
\text { wilfully reverse the direction of his } \\
\text { nystagmus by trying to look with either } \\
\text { eye. }\end{array}$ & Right \\
\hline
\end{tabular}

originally presented at 6 months of age with nystagmus. At 18 months of age a conspicuous head turn to the left and a right convergent squint were noted. The retinas and optic discs were normal. Visual evoked potentials (VEPs), electroretinograms (ERGs), and computed tomography (CT) scans were also normal. He was diagnosed as having congenital idiopathic nystagmus. There was no relevant family history. In the light there was a conspicuous left beating nystagmus which spontaneously reversed in beat direction when recorded in the dark (Fig 1, case 1). The subject was not aware of the changes in eye movements in the dark and was unable to control or reverse the direction of his nystagmus at will.

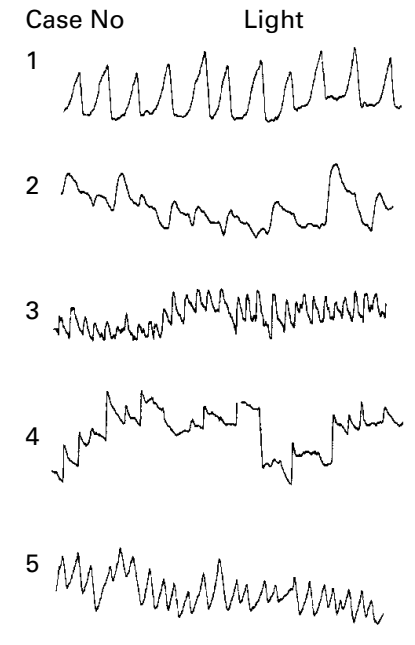

Figure 1 Horizontal eye movement wave forms recorded by bitemporal electro-oculography for cases 1-5. The manifest latent nystagmus in the light is left beating for cases 1 and 5 and right beating for cases 2, 3, and 4. In the dark this nystagmus can be seen to reverse in beat direction. Note that leftward eye movements are recorded as down and rightward eye movements as up.
Case 2

This 4 year old girl was diagnosed as having tuberous sclerosis in early infancy with hypopigmented skin lesions and seizures noted at 2 weeks of age. She was born with the cord around the neck and Apgar scores were 0 at 1 minute, 5 at 5 minutes, and 9 at 10 minutes. There was no relevant family history. Investigations included an EEG, which showed abnormal discharge over the right posterotemporal region, and a computed tomography (CT) scan that showed a hyperdense area in the right occipital lobe. She presented to the ophthalmology department at 4 years of age with a left convergent squint and nystagmus. There was no relative afferent pupillary defect, no refractive error, and the fundi were normal. A right beating nystagmus was recorded in all directions of gaze in the light and this nystagmus reversed in beat direction in the dark (Fig 1 case 2). This patient was unable to wilfully control or change the beat direction of her nystagmus.

Case 3

This child was born with the cord around the neck and face and had facial asymmetry and bruising. She presented to the ophthalmologist at 4 months of age, who noted a flattened side of face, a microphthalmic left eye with an irregular pupil and retinal dysplasia. A fine horizontal nystagmus and a slight head turn to the right were also noted. The right eye was normal except for the nystagmus. Investigations included a CT scan that showed no other abnormalities. VEPs and ERGs were absent from the left eye and normal from the right eye. A cosmetic shell was fitted at 8 months. There was no relevant family history. Eye movements were recorded at 7 years of age (Fig 1 case 3 ). This child was not able to wilfully reverse the direction of her nystagmus in the light or dark or attempt to look with her blind eye. 


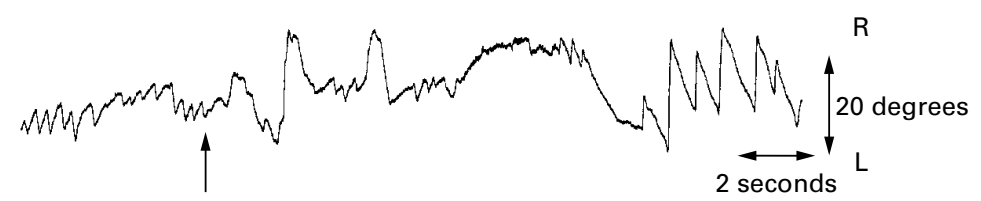

Figure 2 Manifest latent nystagmus recorded in the light in case 5 who has a right ocular prosthesis as a result of anophthalmos. Under usual viewing conditions the nystagmus is left beating; however, when asked to try and look using his blind right eye (up arrow), the nystagmus characteristics change and the beat direction reverses and becomes right beating.

Case 4

The abnormal left eye was noted at birth and he presented to the ophthalmologist aged 18 days. The left eye was found to be microphthalmic with opaque, superficially vascularised cornea. A diagnosis of Peter's anomaly was made. The right eye was normal. A fine small amplitude nystagmus was noted at around 6 months of age. VEPs and ERGs were normal for the right eye. Left eye flash ERGs were normal but VEPs were absent. The only family history is that father has a convergent squint. Eye movements were recorded at 9 years of age (Fig 1 case 4 ). This child reported that his "eyes felt funny and that he felt as if he was spinning around" when he was in the dark. This child could not wilfully reverse the direction of his nystagmus.

Case 5

This child's abnormal right eye was noted at birth and he was referred to the ophthalmologist aged 4 days. A right anophthalmos was diagnosed. The left eye was normal. Horizontal left beating nystagmus was noted at 4 months of age. At the age of 1 year the child developed a left head turn and was fixing and following well. Flash VEPs and ERGs were normal for the left eye but absent for the right. An ocular prosthesis was fitted at 17 months. There was no relevant family history. Eye movements were recorded at 9 years of age (Fig 1 case 5). This child could wilfully reverse the direction of his nystagmus in the light or dark by changing the eye he was intending to look with (Fig 2).

\section{Discussion}

This report describes the unusual finding of five children whose manifest latent nystagmus spontaneously reversed in beat direction when the lights were turned out. Furthermore, one child with a blind eye could on request control the beat direction of his latent nystagmus by attempting to look with his blind eye. The nystagmus in four of the patients had the characteristic waveform of decelerating and linear slow phase velocity and quick phases that were in the direction of the good eye. Case 1 who was diagnosed with a convergent strabismus differed slightly. Although the nystagmus quick phases were in the direction of the better eye with both eyes viewing, and reversed when the better eye was occluded, the slow phases were either of linear or accelerating velocity. Accelerating velocity slow phases are typically the hallmark of congenital nystagmus and it appears that this patient had a mixture of $\mathrm{CN}$ and latent and manifest latent nystagmus.
This combination of waveforms in the same patient is rare but has been described previously ${ }^{67}$ and is compatible with the theoretical model that $\mathrm{CN}$ is due to inherent excessive gain in the smooth pursuit system. ${ }^{8}$

Infrared video recording and assessment of eye movements in the dark is not a common procedure in most centres that see patients with $\mathrm{CN}$ and $\mathrm{LN}$. The finding of five children with spontaneous reversal of nystagmus beat direction in the dark implies that it may be more common than appreciated in strabismic patients or in patients with monocular visual loss and MLN. Over the 1 year period that these five patients were seen, eye movements were recorded in a total of 16 children with congenital profound uniocular defect, of whom seven had MLN (thus 3/7 had reversal of nystagmus beat direction in the dark). Over the same period 31 patients with LN/MLN were recorded and only two showed change of nystagmus beat direction in the dark.

The spontaneous reversal of MLN direction in the dark has been described in an older patient with a congenitally blind eye. ${ }^{4}$ It is assumed that in the dark and with the lack of any visual input, the preferred eye - that is, the dominant eye, establishes the beat direction of the MLN. The spontaneous reversal of nystagmus in 3/5 children with monocular congenital blind eyes in this paper suggests that eye dominance is genetically predetermined and occurs before the pathological event leading to the monocular blindness. These observations also imply that eye dominance is centrally determined and is not altered by the sensory defect. There have been no reports of MLN reversing in the dark in patients with two sighted eyes. The two first cases with squint had MLN beating in the direction of the eye with better Snellen acuity but in the dark the MLN reversed in direction. This is interesting as it implies the squint has occurred in the dominant eye.

Eye dominance with hand dominance has been extensively studied. ${ }^{9-12}$ It is reported that around $65 \%$ of the normal population have ipsilateral eye-hand dominance, $18 \%$ have contralateral or crossed eye-hand dominance, and $17 \%$ have central ocular dominance. ${ }^{13}$ If we assume that in our cases eye dominance is revealed by the spontaneous reversal of the nystagmus in the dark, with the dominant eye determining the MLN beat direction, then 3/5 children (60\%), had ipsilateral hand-eye dominance. This is similar to the reports of normal population studies.

Visual input appears to be the most important factor in determining the direction of the MLN beat direction-when it is removed, by placing the patient in darkness, the MLN waveform spontaneously reverts to its inherent, preprogrammed direction. This occurred passively without any effort by the patient or suggestion by the observers. When the patients were asked to try and control their nystagmus by attempting to look through one eye or the other, both in darkness and in normal lighting conditions, the majority were unable to do so, or failed to comprehend the task. However, one of the older children could exert control over 
his nystagmus by attempting to look through either eye. This patient differed from the previously reported two cases, ${ }^{3}$ who could release and suppress their MLN at will but they could only evoke a nystagmus that beat towards the dominant eye and not towards the amblyopic eye.

The observations described in our patients provide strong support for the important role of a higher cortical component in the generation of LN and MLN. It is the presumed viewing eye and not the actual viewing eye that determines the MLN beat direction. Furthermore the co-existence of $\mathrm{LN}$ and $\mathrm{CN}$ mixed waveforms as found in case 1 implies that a higher cortical attention loop is needed in theoretical models of $\mathrm{CN}$ also. The pathogenesis of LN remains unknown particularly as not all patients with congenital uniocular visual loss and abnormal binocularity develop LN. However, it appears that higher visual attention and egocentric localisation are important factors in LN/MLN generation and when these attentional mechanisms are not called upon (such as being placed passively in the dark), then the LN/MLN reverts automatically to the predetermined state where the dominant eye takes over.

We would like to thank The Iris Fund for their support.
1 Harris CM. Nystagmus and eye movement disorders. In: Taylor D, ed. Paediatric ophthalmology. Oxford: Blackwell Science, 1997:869-96.

2 Kushner BJ. Infantile uniocular blindness with bilateral nystagmus. Arch Ophthalmol 1995;113:1298-300.

3 Kommerell G, Zee D. Latent nystagmus. Release and suppression at will. Invest Ophthalmol Vis Sci 1993:34: 1785-92.

4 Dell'Osso LF, Abel LA, Daroff RB. Latent/manifest latent nystagmus reversal using an ocular prosthesis. Invest Ophthalmol Vis Sci 1987;28:1873-6.

5 Harris C, Kriss A, Shawkat F, et al. The use of video in assessing and illustrating abnormal eye movements in young children. F Audiovis Media Med 1992;15:113-16.

6 Dell'Osso LF. Congenital, latent and manifest latent nystagmus - similarities, differences and relation to strabisnystagmus-similarities, differences and
mus. Fpn f Ophthalmol 1985;29:351-68.

7 Scallan CJ, Abadi RV. Manifest latent and congenital nystagmus waveforms seen in the same patient. Invest Ophthalmol Vis Sci 1997;38:S651

8 Harris CM. Problems in modelling congenital nystagmus: towards a new model. In: Findlay JM, Walker R, Kentridge RW, eds. Eye movement research. Mechanisms, processes and applications. Amsterdam: Elsevier Science, 1995:239-53.

9 Robison SE, Block SS, Boudreaux JD, et al. Hand-eye dominance in a population with mental handicaps: prevalence and a comparison of methods. F Am Optom Assoc 1999;70:563-70.

10 Dellatolas G, Curt F, Dargent-Pare C, et al. Eye dominance in children: a longitudinal study. Behav Genet 1998;28: $187-95$.

11 Bryden MP. Handedness, cerebral lateralization, and measures of "latent left-handedness". Int F Neurosci 1989;44: 227-33.

12 Hebben N, Benjamins D, Milberg WP. The relationship among handedness, sighting dominance, and acuity dominance in elementary school children. Cortex 1981;17:4416.

13 Portal JM, Romano PE. Major review: ocular sighting dominance: a review and a study of athletic proficiency and eye-hand dominance in a collegiate baseball team. Binocul Vis Strabismus Q 1998;13:125-32. 